\title{
Practical E-Learning for the Faculty of Mathematics and Physics at the University of Ljubljana
}

\author{
Primož Lukšič, Boris Horvat, \\ and Andrej Bauer \\ Institute of Mathematics, \\ Physics, and Mechanics, \\ University of Ljubljana, \\ Slovenia
}

primoz.luksic@fmf.uni-lj.si boris.horvat@fmf.uni-li.si andrej.bauer@fmf.uni-li.si

\author{
Tomaž Pisanski \\ Institute of Mathematics, \\ Physics, and Mechanics, \\ University of Ljubljana \\ and University of Primorska, \\ Slovenia
}

tomaz.pisanski@fmf.uni-lj.si

\begin{abstract}
This paper presents the practical issues involved in introducing e-learning for the Faculty of Mathematics and Physics (FMF) at the University of Ljubljana, Slovenia. It begins with a short history of e-learning at FMF and is followed by a discussion about the choice of the open source software (Moodle, svn, wiki platform) as the foundation for the web based learning; its advantages and disadvantages. The focus is on materials that enhance classroom learning, conform to learning standards, and at the same time address the needs of the end users - the students. In the end, the results of a survey about the students' attitudes towards e-learning are presented; in general and specific to the e-learning environment at FMF.
\end{abstract}

Keywords: e-learning, learning management system, LMS, Moodle, MediaWiki, open source, elearning standards.

\section{Introduction}

The expansion of the World Wide Web has had a drastic influence on learning. With the help of software systems known as learning management systems (LMS) and with the introduction of new open standards the concept of e-learning has evolved and became an indispensable supplement or even a replacement for traditional education. Along with learning, teaching has also adapted to changes. Today, e-learning is understood as a term describing an educational setting in

Material published as part of this publication, either on-line or in print, is copyrighted by the Informing Science Institute. Permission to make digital or paper copy of part or all of these works for personal or classroom use is granted without fee provided that the copies are not made or distributed for profit or commercial advantage AND that copies 1) bear this notice in full and 2) give the full citation on the first page. It is permissible to abstract these works so long as credit is given. To copy in all other cases or to republish or to post on a server or to redistribute to lists requires specific permission and payment of a fee. Contact Publisher@InformingScience.org to request redistribution permission. which teaching and learning take place within an Internet-based environment (Berge \& Collins, 1995).

The Faculty of Mathematics and Physics (FMF) at the University of Ljubljana, Slovenia, actively used new types of learning from the very beginning. In 1995, teachers have already created course homepages on the web, but mostly as static HTML pages. By to- 
day's standards, the pages provided a media-poor content and were often cumbersome to manage. Only one content management system from that time, Trubar (Batagelj \& Zaveršnik, 1995), is still operational. Some courses included on-line exercises that needed to be graded. Several adhoc systems were developed to address this issue. As a result, students had to deal with a variety of interfaces and techniques for obtaining course information and homework submission.

In 2005 we started a pilot project with a goal of introducing the modern interactive learning to students and faculty members, and unifying the preparation and dissemination of course materials. We decided to use an open-source solution, i.e., software with freely available source code that anyone may improve and tailor to their needs. This decision proved to be overall a good one, as it helped us to develop solutions that accommodated our specific needs. We had to deal with:

- internationalization of the graphical user interface (GUI),

- integration of the repository of course materials with Subversion (http://subversion.tigris.org/),

- extending the functionality of the LMS with new packages,

- integration with LaTeX (http://www.latex-project.org/),

- $\quad$ integration with wiki.

At first (March 2005), we used two systems in parallel: Plone (http://www.plone.org) and Moodle (http://moodle.org). The first is a general content management system from which an educational portal can be build, while the seconds is an out-of-the-box course management system. A year later we selected Moodle as the preferred one. It turned out to be quite popular in other environments, too. It is used by government institutions such as Zavod RS za šolstvo, as well as in a number of Slovenian high schools and universities (Pehan \& Vehovar, 2006).

When we set up the Web Classroom (Spletne učilnice FMF) at http://ucilnica.fmf.uni-lj.si as our Moodle-based e-learning environment, we encountered several design and management questions:

- Is it better to keep all course materials from the last year and build on top of them, or set up a new environment every year?

- How to archive and manage the knowledge produced each year in such a way that students and teachers could easily use it?

- What type of standardization of learning objects should be used?

We discuss these topics in the following section.

While the students quickly adopted the new e-learning environment, the response by the teachers was somewhat slower. During the year, the Web Classroom eventually became recognized by the members of the mathematics department as a useful addition to conventional ways of teaching and is now used mostly for web-enhanced courses (MacEntee \& Lewis, 2004).

Today, the Web Classroom contains almost a hundred courses, comprising of undergraduate and graduate classes in mathematics, computer science and physics, undergraduate classes in mathematics that are held at other faculties in Slovenia, research seminars and research projects. Students can participate from the internet and the vast majority of the knowledge is available to unregistered users - guests.

In November 2006, we carried out a student survey about the Web Classroom. The results presented in this paper will play an important role in creating an even better e-learning environment, 
with the hope that online learning someday replaces or becomes equivalent to the in-class seat time.

\section{The Road to E-Learning}

A number of results show the usefulness of e-learning (MacEntee \& Lewis, 2004), of which we mention two aspects:

- Web enhanced courses combine advantages of synchronous learning where learning and teaching takes place in real time with asynchronous learning where learning and teaching takes place with a time delay.

- Web enhanced courses move students away from being passive recipients of knowledge to becoming more actively engaged in the construction of knowledge.

E-learning thus makes the process of learning interactive and collaborative, less time-dependent and not subject to geographic location, which makes it time- and cost-effective for students (Sajko, Rabuzin, \& Hutinski, 2006).

\section{The Learning Environment}

When our project of e-learning started in September 2005, the first important decision was to select a good software. Since so many content management systems for e-learning were already available, it was clear that we would select one rather than trying to develop our own solution. An open-source environment was an obvious choice since it is freely available and possesses the benefits described in Coppola and Neelley (2004), such as rapid evolution, collaboration of the user community, and enhanced security due to source code availability.

We selected the Moodle content management system since it offered several advantages. The most important was its large community, which currently comprises more than 150,000 registered users, and good support for internationalization. Presently, Moodle is translated to over 75 languages. Moodle was already present in Slovenian schools before 2005 (Raba Interneta V Sloveniji, 2005), which made it even more appealing.

Incidentally, the word moodle is an acronym for Modular Object-Oriented Dynamic Learning Environment. Modular design allows users to add various learning activities by installing customized software units, called modules. This makes the application easier to develop and maintain.

There are a number of evaluations of (open-source) learning management systems available in literature and on the Internet; e.g., Edutech's evaluation (2005) at http://www.edutech.ch/lms/ev3/. Most LMS applications include standard learning tools such as quizzes, forums, calendars, surveys, real-time chats, grading tools, etc. The main difference between them is in the way they are available to the learner. Successful ones emphasize usability over functionality since usability seems to be the prevailing factor determining the success of an online course (Lewis et. al., 2005). Moodle interface is quite intuitive. We have not encountered any usability issues among students who quickly got used to Moodle and started participating actively in course activities. Also, in Kareal and Klema (2006), Moodle and DotLRN (http://dotlrn.org/) were selected as the most flexible e-learning systems.

\section{Extending the Scope}

With the installation of Moodle our primary goal of providing an easy to use learning environment that conforms to the requirements of both students and teachers was generally accomplished. However, we also had several specific needs that were not met: 


\section{Collaboration}

Besides providing collaboration between students and lecturers through forums, chat rooms, exercises, etc., we also needed a way of tracking the history of changes in course materials and synchronization between changes made by different teachers of the same course.

This problem was solved by integrating a version control system Subversion (SVN) with Moodle. Subversion, which is the next generation of the well known Concurrent Version Systems (CVS), allows users to work on the same files simultaneously. Each user can edit the files within his copy of a repository, and later report the changes to the central archive. We integrated this into Moodle so that a copy of the repository is visible through Moodle. Effectively this means that the latest copy of the materials is always present in the Web Classroom. When a teacher commits his changes to the central archive, the Moodle copy refreshes its content to reflect the changes. This allows several teachers to work on the materials simultaneously without worrying about possible conflicting changes since Subversion takes care of those.

Since Moodle intensively uses the relational database, this only covers the part of the wide spread problem. Important data, e.g. quizzes, exercises, assignments, etc. are stored only in the Moodle database and cannot be easily integrated into a version control system. We are currently investigating this issue.

We came to the conclusion that learning environments from previous years contain information that should be available to students and teachers even after the end of a school year (e.g. there are classes that are spanning over two years; sometimes, students can take an exam long after the end of a course; forums sometimes contain useful information; ...). Thus, at the beginning of a new school year the current Moodle instance is copied to a new URL location, where it remains to operate. The data of the current instance becomes hidden and teachers are asked to make the modifications that are needed at the beginning of a new school year.

\section{Knowledge repository}

Early on, we noticed that many activities were replicated among teachers of similar courses. For example, many teachers created very similar lectures, quizzes, and glossaries. It made sense to unify the efforts. We found out that Moodle's design made sharing of small units of course materials among teachers rather cumbersome, so we began looking for a solution outside Moodle.

We decided to create a wiki (a wiki is a web site of interconnected pages that anyone can edit) devoted to our curriculum, in addition to the Web Classroom. We used the MediaWiki platform (http://www.mediawiki.org), which is the software base for the internet encyclopedia Wikipedia (http://en.wikipedia.org/). With the creation of the first page on December 1, 2005, we started to transfer the knowledge from the Web Classroom to the MaFiRa wiki (http://wiki.fmf.uni-lj.si) with the purpose of creating an online encyclopedia of knowledge that was shared among all teachers and students from our faculty. However, we quickly realized that our view was too narrow: there was nothing preventing us from inviting other math, physics and computer departments in the country to cooperate. While the potential for such an approach is clear, we yet have to see active participation from other institutions.

We extended the MediaWiki platform with better support for mathematical notation, graph drawing, and visual presentation of custom project statistics. In the first year of its existence, MaFiRa grew to 1,500 articles with more than 500 registered users. A diagram of growth in time is displayed in Figure 1.

MaFiRa differs significantly from Wikipedia, and its Slovene cousin Wikipedija (http://sl.wikipedia.org/). On Wikipedia the norm is to write encyclopedic, exhaustive articles, while for teaching purposes it is better to have a number of short, interconnected articles, each 


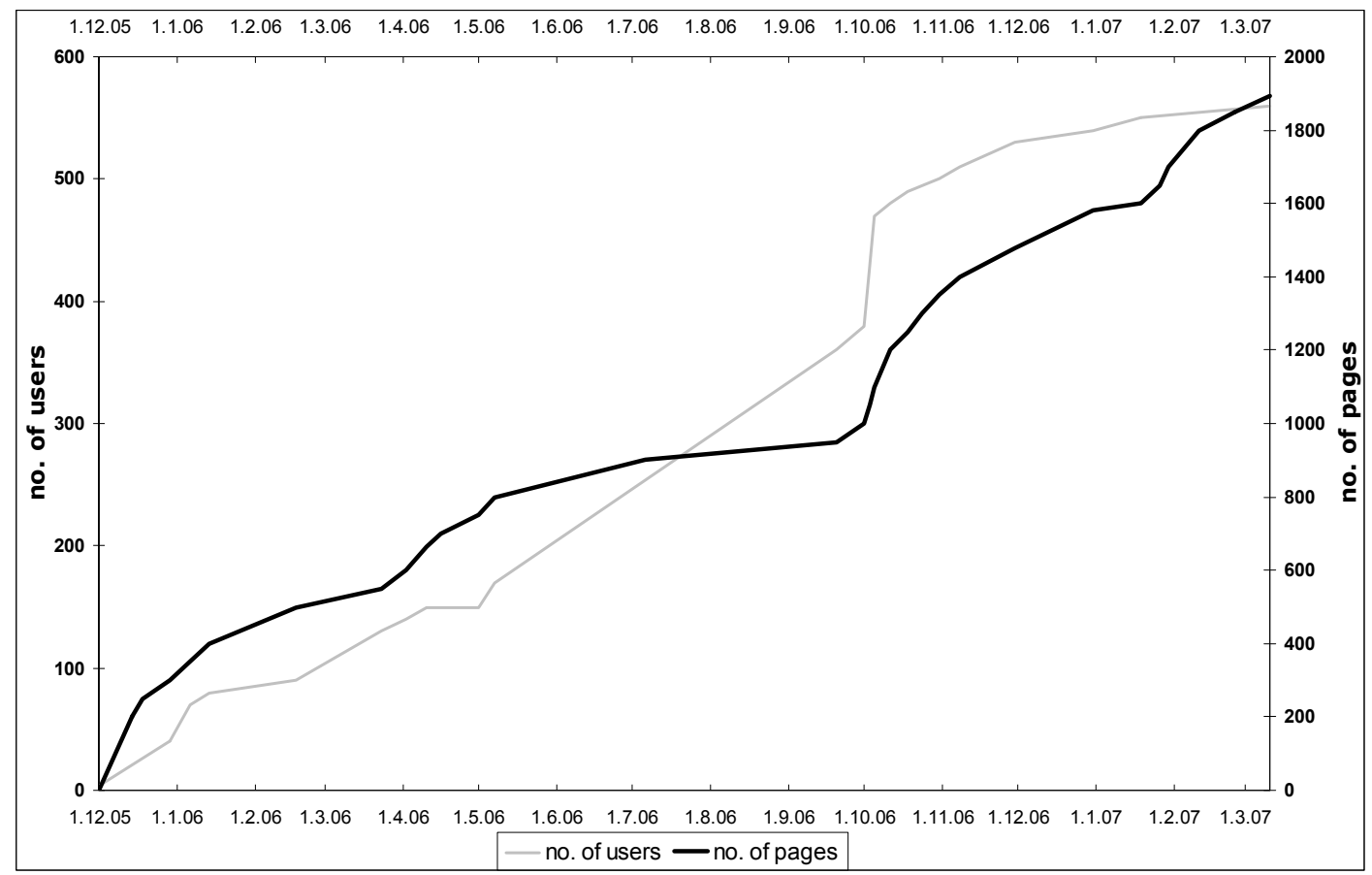

Figure 1: The growth of MaFiRa wiki

presenting only about a very narrow concept. This way the teacher can easily combine the articles into exactly the sort of lecture he/she wants. Our wiki also includes exercises with solutions, computer programs, past exams, and other educational materials.

By its design, a wiki encourages participation of all users. In this sense, it invites the students to become truly involved in the courses they take, as they can modify and improve the course materials by themselves. When conflicts arise, they can be discussed on the discussion page that accompanies each article. In addition, the history of modifications enables anyone to see and possibly revert the changes made to an article. Through the use, attempts to randomly modify the contents have been noticed. These were done by spam robots. With the help of the history, we were able to successfully revert the changes.

The students are aware that the content in MaFiRa can be changed by anyone and thus not be accurate. So far, there have not been any problems with this; on the contrary, the students themselves are frequently improving each other's articles.

\section{Standards}

We also addressed the standardization of e-learning. With the expansion of online courses, there is a need to make the learning objects independent of the environment in which they are used (interoperability) while tracking the learner's progress (manageability).

There are many standards currently available that offer an integration of a number of existing specifications for content description (metadata), content packaging and learner management (Friesen, 2005). The most known to us is SCORM (Sharable Content Object Reference Model) offered by Advanced Distributed Learning initiative (http://www.adlnet.org).

Moodle LMS has support for importing content conforming to SCORM standards but no options to export the content in any of the standards. Work to integrate support for IMS LD is under way 
but there is no mention of support for the export in SCORM. Therefore, all currently created learning materials in Moodle can be reused only in a learning environment that uses Moodle.

With interoperability in mind, we decided to look for the possible ways to implement e-learning standards in our online classes. We examined some of the open source LMS that offer export of content in SCORM or the IMS standards (http://www.imsglobal.org). These were ATutor (http://www.atutor.ca/) and ILIAS (http://www.ilias.de/ios/index-e.html). We found out that none of these is suitable to replace our current system since some difficulties with the use of e-learning standards in practice were discovered. SCORM, for example, has no rules about visual presentation, no possibility for collaborative work and no limitations on the type of files included in such learning objects.

We also tried using open-source software especially designed to produce content that conforms to the mentioned standards. The only useful product was eXe - eLearning XHTML editor (http://exelearning.org/) produced visually stunning, multimedia rich content but still not using the full potential the standards are offering.

It seems there is still a long way before the e-learning standards become accepted in the opensource communities. The e-learning communities all over the world should therefore become aware of the new standards and be offered support to better understand them and apply them to their e-learning processes (Varlamis \& Apostolakis, 2006).

\section{Examining the Response}

With the use of the Web Classroom in its second year, we decided to conduct a non-obligatory online survey of the undergraduate students' attitudes toward e-learning, the Web Classroom and MaFiRa wiki. We wanted to obtain their point of view and experiences in using the offered elearning products with the goal of adapting the e-learning process to their needs even more in the next years.

In the school year 2006/07 there are 453 students enrolled in the programs of mathematics at FMF and $230(50.8 \%)$ of them decided until now to participate in the survey.

When asked whether they used the Web Classroom in the previous year, 125 (54.3\%) answered positively and another 68 students $(29.6 \%)$ stated they are in their first year of studies. As the reason why they use the Web Classroom, a staggering $87 \%$ mentioned the amounts of useful information they receive there and $40 \%$ (it was a multiple-choice question) expressed that it was obligatory for them to use it.

The next scope of questions measured students' responses to statements about e-learning in general and about Web Classroom. They had to provide they answers from a scale of 1 to 4 , where 1 meant they disagree, 2 that they partially agree, 3 was used if they agreed in most aspects of the statement and 4 when they fully agreed with the statement. The average results from all 187 students are shown in Table 1 and Table 2.

Table 1: General student views about e-learning

\begin{tabular}{|l|c|}
\hline $\begin{array}{l}\text { The use of advanced information technology is nowadays necessary in the process } \\
\text { of e-learning. }\end{array}$ & 3.4 \\
\hline $\begin{array}{l}\text { Online learning environments will some day fully substitute the standard forms of } \\
\text { education. }\end{array}$ & 2.3 \\
\hline Online learning saves time and money. & 2.6 \\
\hline Online learning is not only useful in schools but also for other types of education. & 3.4 \\
\hline Payable online courses are better than the free ones. & 1.8 \\
\hline
\end{tabular}


The results of Table 1 are not surprising but it is interesting that students do not find e-learning particularly timesaving activity. This could be explained since the courses are still in a large way web enhanced, thus offering only a supplement to the available type of education. In addition, it seems the students do not think that non-free courses are better than free ones (note that we do not offer payable courses to students at this time).

Table 2: Student views about the Web Classroom

\begin{tabular}{|l|c|}
\hline The Web Classroom makes the process of learning quicker and more efficient. & 2.9 \\
\hline $\begin{array}{l}\text { The Web Classroom solves the problems of finding study literature, old exams, } \\
\text { exercise deadlines etc. }\end{array}$ & 3.5 \\
\hline The Web Classroom is easy to use. & 3.6 \\
\hline The Web Classroom is a helpful asset in the study process. & 3.7 \\
\hline $\begin{array}{l}\text { The lecturers post the course materials, exercises and exam dates quickly and on } \\
\text { time. }\end{array}$ & 3.0 \\
\hline
\end{tabular}

The most important result from Table 2 is that there is a strong belief between the students about the usability of the Web Classroom, thereby confirming our primary goal. As noted before by Lewis (2003), the students will become frustrated with the learning process if they are not able to easily navigate through the course materials. The Moodle LMS in out opinion offers an ease of use.

The following question asked about the frequency of use of the Web Classroom. Almost seventy percent (160) of the students said they use the virtual classroom on a weekly base and $21.3 \%$ (49) are daily users. The usage of the Web Classroom can be also seen from the statistics made on the site. Figure 2 shows that on an average day in November 2006, around 3,000 activities were recorded by students and around 500 activities by lecturers. Observe that the curves follow the same pattern.

The last question about the Web Classroom asked the students about the things they are missing there. A whole $80 \%$ (149) would like to have even more course materials available online and $42.8 \%$ (80) want more interactive activities (quizzes, discussions, etc.).

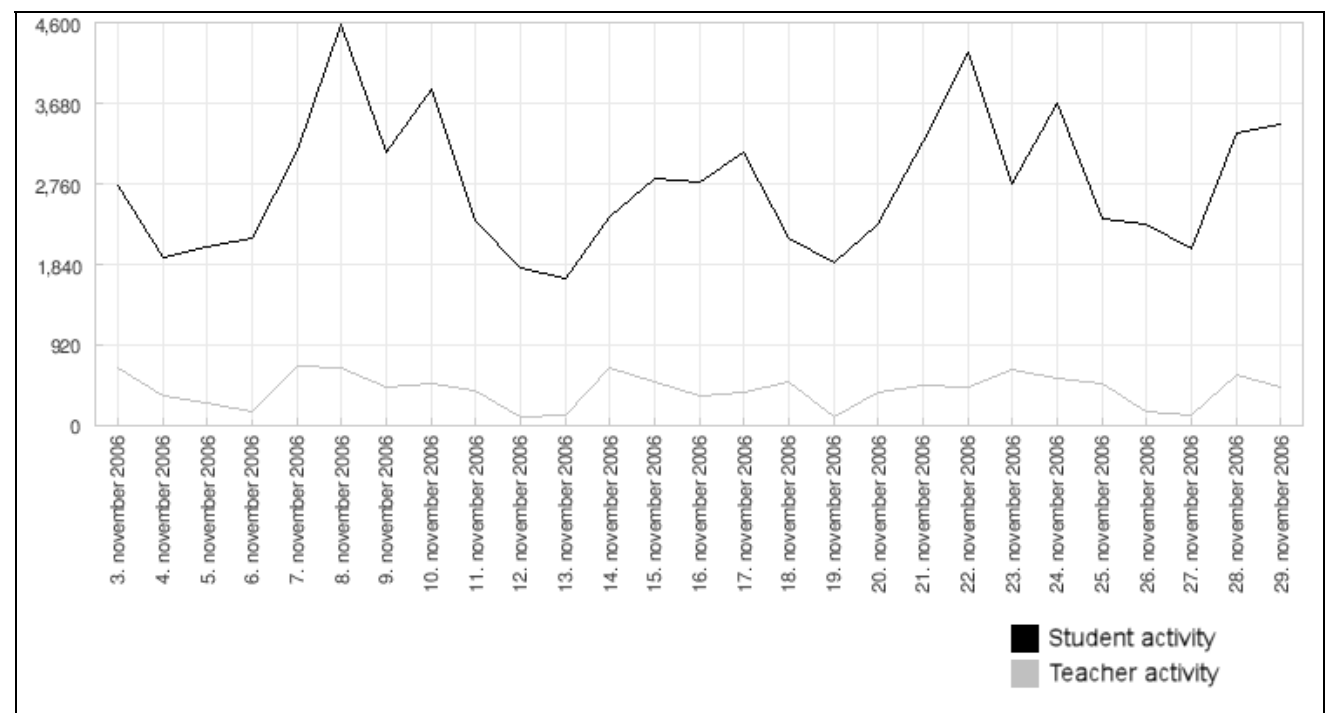

Figure 2: The usage of the Web Classroom in November 2006 
The next set of questions was about the MaFiRa encyclopedia. First, the students were enquired if they even know about its existence. The answers were almost equally divided as seen in Table 3 . The reason for such replies is in the fact that MaFiRa is still unofficial and its use is not promoted to the students.

Table 3: The use of MaFiRa online encyclopedia

\begin{tabular}{|l|l|}
\hline I use it and contribute to it. & $22.6 \%$ \\
\hline I use it but do not contribute to it. & $29.1 \%$ \\
\hline I heard of it but I do not use it. & $28.7 \%$ \\
\hline Today is the first time I hear of it. & $19.6 \%$ \\
\hline
\end{tabular}

Students also shared their opinions about the purpose of MaFiRa wiki with $77.8 \%$ (179) claiming it can be helpful when studying. They also approved of its policy of letting anybody contribute to it (38.3\%) and noted it could someday replace other literature (25\%). Only 5\% answered that such encyclopedia is not needed. As seen from the answers, this was a multiple-choice question. At the end, we asked the students what would persuade them to use the MaFiRa more frequently. Around 68\% (157) replied they would use it if there already were a good database of articles, exercises and computer programs available.

The most surprising fact of all was the response of students in places where they were allowed to make their own commentaries and express their own opinions. About $20 \%$ had something to add besides the prearranged answers, which makes a valuable contribution for making the online learning experience even better.

\section{A Wider View}

The University of Ljubljana (http://www.uni-lj.si) has more than 56,000 undergraduate and graduate students and approx. 3500 teachers and researchers. It consists of 22 faculties (departments), 3 academies of art and 1 university college. There are also two other (younger and smaller) universities in Slovenia, the University of Maribor and the University of Primorska. Since the University of Ljubljana is among the biggest universities in the world and at the same time highly decentralized, implementing a central virtual learning environment for a whole university was not applicable. Thus, the faculties addressed this issue by their selves and FMF was among the pioneers of this field.

In March 2007, the Web Classroom at FMF contained 96 courses, comprising of undergraduate and graduate classes in mathematics and computer science (50), undergraduate classes in physics (6), undergraduate classes in mathematics that are held at other faculties (11), research seminars and research projects $(8)$, where

- al least 72\% (50 out of 69) of all classes in mathematics and computer science that are held at FMF have web pages with course information that changes during the semester (some are still not included in the Web Classroom),

- $72 \%$ (50 out of 69 ) of all classes in mathematics and computer science that are held at FMF are presented on the internet in such a way that students can actively cooperate, 
This is a great achievement compared to other higher education institutions in Slovenia, where (Pehan \& Vehovar, 2006):

- $58 \%$ of all courses in Slovenian higher education have web pages with course information that changes during the semester,

- $26 \%$ of all courses in Slovenian higher education are presented on the Internet in such a way that students can actively cooperate,

- $16 \%$ of all courses held at the University of Maribor and only $4 \%$ of all courses held at the University of Ljubljana have a virtual teaching environment.

Furthermore, almost all classes are freely available to the visitors, thus reflecting our policy to share the knowledge among all who are interested. While this could be said to be true since we have no tuition fee, there are universities in the world who are beginning to offer their course materials freely although their students have to pay tuition fees, e.g. MIT's OpenCourseWare (http://ocw.mit.edu).

\section{The Road Ahead}

The results of the survey will be thoroughly examined and incorporated in the strategy of improving and extending the online courses. Another survey is also being preformed to get the lecturers' opinions on e-learning. The results will help us maintain the usability of the Web Classroom while striving for the next goal of providing all of the available classes as web-enhanced classes. Later we will use the modern audio-video equipment to produce hybrid classes, similar to Bodendorf, Schertler and Cohen (2005), where some of the standard learning will be replaced by online learning. The last step of the project is to offer a fully online course supported by a next generation of virtual classrooms, which is not offered at this time.

As noted by Oblinger, Barone and Hawkins in 2001, the new technology will transform higher education, as we know today. In our opinion, the new technology is already affecting and transforming the whole field of education, not just the higher education. Our goal is to remain a part of this transformation and provide the best e-learning environment to our students and teachers by remaining a forerunner in exploring and facilitating the use of e-learning in Slovenia

\section{References}

Batagelj, V., \& Zaveršnik, M. (1995). Trubar content management system [Computer software]. Available from http://www.educa.fmf.uni-lj.si/trubar/

Berge, Z.L., \& Collins, M. (Eds.). (1995). Computer-mediated communication and the online classroom. Cresskill, NJ: Hampton Press.

Bodendorf, F., Schertler, M., \& Cohen, E. (2005). Producing Reusable Web-Based Multimedia Presentations. InterdisciplinaryJournal of Knowledge and Learning Objects, 1, 127-142. Retrieved March 10, 2007, from http://www.ijklo.org/Volume1/v1p127-142Bodendorf.pdf

Coppola, C., \& Neelley, E. (2004). Open source open learning: Why open source makes sense for education. Retrieved March 10, 2007, from http://www.rsmart.com/assets/OpenSourceOpensLearningJuly2004.pdf

Edutech. (2005). Evaluation of open source learning management systems. Retrieved March 10, 2007, from http://www.edutech.ch/lms/ev3/

Friesen, N. (2005). Interoperability and learning objects: An overview of e-learning standardization. Interdisciplinary Journal of Knowledge and Learning Objects, 1, 23-31. Retrieved March 10, 2007, from http://ijklo.org/Volume1/v1p023-031Friesen.pdf 
Kareal, F., \& Klema, J. (2006). Adaptivity in e-learning. IV International Conference on Multimedia and Information and Communication Technologies in Education. Retrieved March 10, 2007, from http://www.formatex.org/micte2006/Downloadable-files/oral/Adaptivity\%20in\%20e-learning.pdf

Lewis, B. (2003). Blackboard course design: The "One Click" methodology. Brazilian Review of Open and Distance Learning Journal, 2(3). Retrieved March 10, 2007, from http://www.abed.org.br/publique/cgi/cgilua.exe/sys/start.htm?UserActiveTemplate=2ing\&infoid=884 $\underline{\text { sid }}=137$

Lewis, B., MacEntee, V., DeLaCruz, S., Englander, C., Jeffrey, T., Takach, E., et al. (2005). Learning management systems comparison. In Proceedings of the Informing Science and Information Technology Education Joint Conference, Flagstaff, AZ, USA. Retrieved March 10, 2007, from http://proceedings.informingscience.org/InSITE2005/P03f55Lewis.pdf

MacEntee, V. M., \& Lewis, B. A. (2004). Web-enhanced course. Journal of Issues in Informing Science and Information Technology, 1, 951-964. Retrieved from http://articles.iisit.org/121macen.pdf

Oblinger, D., Barone, C.A., \& Hawkins, B.L. (2001). Distributed education and its challenges: An overview. Washington, DC: American Council on Education (ACE). Retrieved March 10, 2007, from http://www.acenet.edu/bookstore/pdf/distributed-learning/distributed-learning-01.pdf

Pehan, V., \& Vehovar, V. (2006). E-izobraževanje 2005/2006 - visokošolski in višješolski zavodi. Raba interneta v Sloveniji (RIS) [E-learning 2005/2006 - higher education institutions. The use of the Internet in Slovenia]. Retrieved March 10, 2007, from http://www.ris.org/index.php?fl=2\&lact $=1 \&$ bid $=1293 \&$ parent $=13 \&$ cat $=75 \& p 1=276 \& p 2=285 \& i d=288$

Raba Interneta v Sloveniji (RIS project). (2005). Available from http://slovenia.ris.org and http://www.ris.si

Sajko, M., Rabuzin, K., \& Hutinski, Ž. (2006). Sistemski razvoj elektronskega učenja v visokošolski izobraževalni ustanovi [Systematic approach to e-learning in a higher education institution]. Organizacija, 39(2), 97-107.

Varlamis, I., \& Apostolakis, I. (2006). The present and future of standards for e-learning technologies. Interdisciplinary Journal of Knowledge and Learning Objects, 2, 59-76. Retrieved from http://ijklo.org/Volume2/v2p059-076Varlamis.pdf

\section{Biographies}

Primož Lukšič is a junior researcher at the Institute for Mathematics, Physics and Mechanics in Ljubljana, Slovenia. He is a Ph.D. student at the Faculty of Computer Science in Ljubljana. His interests range from discrete mathematics to theoretical computer science and the practical use of web technologies. He is a supervisor of the e-learning environment at the Faculty of Mathematics and Physics in Ljubljana and is actively researching and testing the new learning technologies.

Boris Horvat is a junior researcher at the Institute for Mathematics, Physics and Mechanics in Ljubljana, Slovenia. He is a Ph.D. student at the Faculty of Computer Science in Ljubljana. His research interests range from discrete mathematics to theoretical computer science, project management, e-learning and entrepreneurship. He is one of the supervisors of the e-learning environment at the Faculty of Mathematics and Physics in Ljubljana and is actively researching and testing the new learning technologies. He has a lot of experience in fields close to the Internet, multimedia, programming and system integration.

Dr. Andrej Bauer received his Ph.D. in Computer Science from the Carnegie Mellon University. His research fields are constructive and computable mathematics. Being a lecturer at the Faculty of Mathematics and Physics (FMF) in Ljubljana, Slovenia, he is always promoting new ways of teaching and has had a major role in establishing a virtual learning environment at FMF. 
Dr. Tomaž Pisanski is a professor of discrete and computational mathematics at the University of Ljubljana and the University of Primorska. He is a Slovenian mathematician working mainly in graph theory, discrete mathematics and theoretical computer science. He has been one of the pioneers in setting up the e-learning environment at the Faculty of Mathematics and Physics in Ljubljana and is actively promoting the usage of new information technologies. 